\title{
West Nile virus surveillance in mosquitoes, April to October 2013, Vojvodina province, Serbia: implications for the 2014 season
}

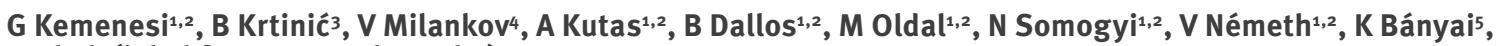

F Jakab (jakabf@gamma.ttk.pte.hu) ${ }^{1,2}$

1. Virological Research Group, Szentágothai Research Center, University of Pécs, Pécs, Hungary

2. Institute of Biology, Faculty of Sciences, University of Pécs, Pécs, Hungary

3. Ciklonizacija Ltd., Novi Sad, Serbia

4. Department of Biology and Ecology, Faculty of Sciences, University of Novi Sad, Novi Sad, Serbia

5. Institute for Veterinary Medical Research, Centre for Agricultural Research, Hungarian Academy of Sciences, Budapest, Hungary

Citation style for this article:

Kemenesi G, Krtinić B, Milankov V, Kutas A, Dallos B, Oldal M, Somogyi N, Németh V, Bányai K, Jakab F. West Nile virus surveillance in mosquitoes, April to October 2013, Vojvodina province, Serbia: implications for the 2014 season. Euro Surveill. 2014;19(16):pii=20779. Available online: http://www.eurosurveillance.org/

ViewArticle.aspx?Articleld $=20779$

Article submitted on 09 April 2014/ published on 24 April 2014

After the West Nile virus (WNV) outbreak in 2012, we collected mosquito samples from Vojvodina province, Serbia, in 2013. We found high WNV infection rate in two species, Culex pipiens and Anopheles maculipennis. Phylogenetic analysis showed that Serbian WNV strains from 2013 were most closely related to Italian and Greek strains isolated in 2012 and 2010, respectively. Public health authorities should be aware of a potentially increased risk of WNV activity during the 2014 season.

In this report we provide evidence for an unprecedented detection rate of West Nile virus (WNV) in competent mosquito vectors during the 2013 season. Given that these arthropods overwinter, our WNV surveillance of mosquitoes collected during the 2013 season of high mosquito activity (April to October) from Vojvodina province, Serbia, may have implications for the preparation for the WNV season in 2014 .

WNV has been documented in Serbia since the 1970 S by seroepidemiological surveys and was detected in Culex pipiens mosquitoes during a mosquito surveillance programme conducted in $2010[1,2]$. After the 2012 epidemic, which was associated with WNV lineage 2 and caused 58 human cases in Serbia (eight of them fatal), the virus was successfully detected and characterised in migratory bird samples [3]. Based on phylogenetic analyses it appeared likely that WNV lineage 2 was introduced on two independent occasions $[3,4]$. The 2012 season was followed by a more severe epidemic season in 2013 with over 300 human cases. In the absence of information about strains causing the WNV outbreak in Serbia during 2013, it was not possible to elucidate whether the 2012 strains circulated and overwintered to cause epidemics in the consecutive year. [5]. The aim of the present study was to detect and characterise WNV strains circulating in the 2013 mosquito activity season in Vojvodina.

\section{Mosquito collection}

Center for Disease Control and Prevention (CDC) light traps baited with dry ice were placed at 13 sampling sites in Vojvodina province, Serbia, between April and October, 2013. Between four and six traps were used at each sampling site and operated overnight (from 19:00 to 07:00). Altogether, 25 overnight sampling events were conducted during the study period. Sites were sampled as part of the Serbian seasonal mosquito control activities in Vojvodina. Site selection and the number of sampling events directly correlated with the human-inhabited areas or mosquito breeding sites. Sampling sites and collection dates are shown in Figure 1. To obtain the most reliable virological results, traps were emptied immediately after each 12-hour period, and collected specimens were placed on dry ice. Mosquitoes were kept frozen at $-80{ }^{\circ} \mathrm{C}$ until processing in the laboratory.

\section{Laboratory analysis}

Mosquitoes were determined by species according to their taxonomic keys [6] and female mosquitoes were finally pooled by collection site, date and species, with a maximum of 50 individuals per pool. Mosquitoes were homogenised in sterile $600 \mu \mathrm{L}$ phosphate-buffered saline, viral RNA was extracted from $200 \mu \mathrm{L}$ of supernatants using DiaExtract Total RNA Isolation Kit (DIAGON Ltd., Hungary). Samples were tested with a TaqMan real-time RT-PCR targeting the NS3 region of WNV, using reagents of the OneStep RT-PCR Kit (Qiagen) [7]. Representative strains from each sampling location were re-amplified with primers targeting a longer fragment of the NS3 genomic region [8]. The amplicons were directly sequenced (BigDye Terminator v1.1 Cycle Sequencing Kit in ABI Prism 310 DNA Sequencer 
Location of mosquito sampling sites $(n=13)$ and collection dates for West Nile virus surveillance, Vojvodina province, Serbia, April-October 2013

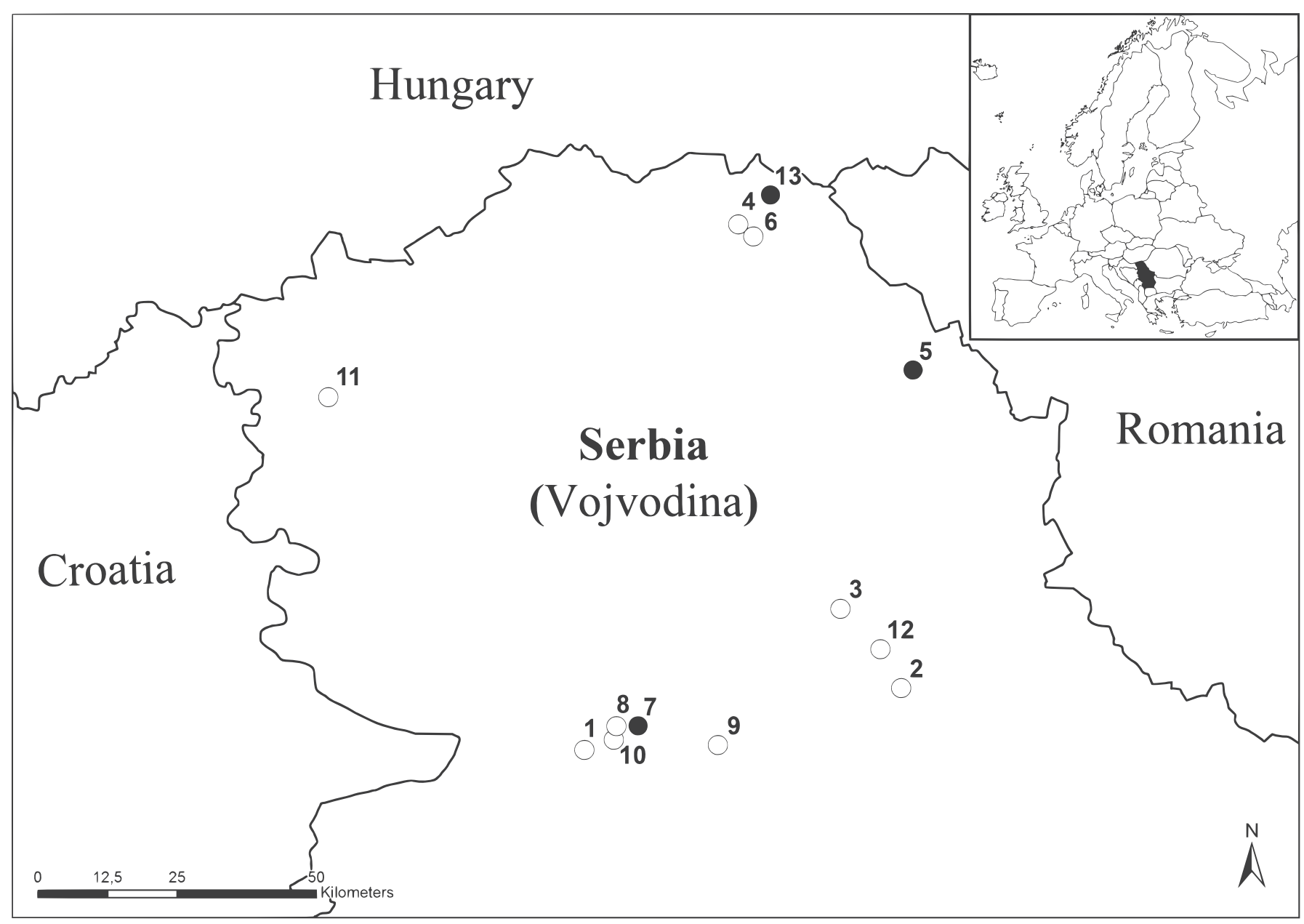

WNV: West Nile virus.

Black dots represent WNV-positive mosquito collection sites.

5: Kikinda, August 13 August;

7: Novi Sad, 16 June, 29 June, 9 July, 22 July, 1 August, 12 August, 17 September, 2 October;

13: Srpski Krstur, 20 July.
White dots show the negative sampling sites.

1: Beočin, 3 July;

2: Ečka, 9 May;

3: Elemir, 9 May, 4 June, 13 July;

4: Kanjiža, 20 July;

6: Novi Kneževac, 20 July;

8: Novi Sad rural territory. 1 August, 15 August;

9: Kovilj, 22 July;

10: Novi Sad urban territory, 2 October;

11: Sombor, 16 April;

12: Zrenjanin, 9 May, 14 June, 12 July. instrument, Applied Biosystems) and the obtained sequences were used in phylogenetic analysis.

\section{Vector detection}

A total of 6,369 female mosquitoes (combined in 180 pools) representing 11 species were tested in this study (Table). Ten ( $5.5 \%)$ of 180 pools (minimal infection rate (MIR) value: 1.57 ) sampled were positive for WNV RNA. WNV was detected in nine pools of C. pipiens (MIR value: $1.61 ; 95 \%$ confidence interval: $0.70-3.10)$ and a single pool of Anopheles maculipennis (MIR value: 45; $95 \%$ confidence interval: $1.20-228.40$ ), suggesting that these two mosquito species may play an important role of WNV transmission in the study area.

Mosquitoes tested positive for WNV were collected in July and August, at sampling sites in Kikinda (four positive pools) ( $45^{\circ} 48^{\prime} 56.51^{\prime \prime} \mathrm{N}$; $\left.20^{\circ} 25^{\prime} 18.24^{\prime \prime} \mathrm{E}\right)$, Novi Sad (five positive pools) ( $\left.45^{\circ} 13^{\prime} 36.10^{\prime \prime} \mathrm{N} ; 1^{\circ} 49^{\prime} 30.41^{\prime \prime} \mathrm{E}\right)$ and Srpski Krstur (one positive pool) (46 6'39.68” N; 
$20^{\circ} 7{ }^{\prime} 51.76$ ” E). The number of collected C. pipiens mosquitoes and the monthly distribution of WNV-positive pools followed a similar profile over time as the mean temperature (Figure 2).

Of the 10 WNV positive pools, four representative strains were selected for further phylogenetic analyses: two strains from Kikinda and one strain each from Srpski Krstur and Novi Sad. In the phylogenetic tree, the Serbian WNV strains (KJ652314-KJ652317) clustered with other WNV lineage 2 sequences, but unambiguously separated from other lineages (Figure 3). The analysis based on the NS3 gene showed that Serbian strains were distinct from each other according to geographic locations, i.e. Kikinda, Srpski Krstur and Novi Sad. WNV sequences from 2013 showed a longer phylogenetic distance from those isolates derived from the same region in 2010 and 2012. The 2013 Serbian WNV strains were most closely related to sequences from Italy and Greece with the greatest nucleotide similarity $98-100 \%$ and $98-99 \%$, respectively.

\section{Discussion}

In the present mosquito-based surveillance of WNV we found a high infection rate in two mosquito species, C. pipiens and A. maculipennis in the Vojvodina province, Serbia. These two species have previously been identified as competent vectors of WNV in Europe [9]. The overall $5.5 \%$ positivity are consistent with an MIR of 1.61 for C. pipiens and of 45 for A. maculipennis, which is higher than described in many other European mosquito-based surveillance studies $[10,11]$. Detection of WNV in A. maculipennis in Serbia is a valuable observation, although not unprecedented in Europe [12]. It is important to investigate the role of this species in WNV transmission in the future. The numerous cases of confirmed human infections in 2013 along with the high infection rate of mosquitoes in the same year well demonstrate remarkable activity of the virus [5]. Two WNVpositive sampling sites, Kikinda and Srpski Krstur, are close to the borders with Hungary and Romania. The situation may therefore represent a threat to human health not only in Serbia but also in neighbouring countries, if the ecological conditions in those areas are favourable for mosquito populations.

Phylogenetic analysis showed that Serbian WNV strains from 2013 were most closely related to Italian and Greek WNV strains isolated in 2012 and 2010 and were more diverse than strains identified in 2010 (KC496016) and 2012 (KC407673) in Serbia. Previous studies found at least two different genetic clusters of lineage 2 WNV that circulated simultaneously in Serbia in 2012, suggesting that WNVs were introduced to the country by at least two different events [4]. Phylogenetic analyses with the WNV strains detected from mosquitoes in the present study point to a potential third independent introduction event of the virus.

WNV is typically a seasonal disease strongly associated with mosquito activity. Surveillance of WNV relies
TABLE

West Nile virus surveillance in mosquitoes in Vojvodina province, Serbia, April-October $2013(n=6,369)$

\begin{tabular}{|l|c|c|}
\hline Species & $\begin{array}{c}\text { Number of collected } \\
\text { mosquitoes }\end{array}$ & $\begin{array}{c}\text { Number of tested } \\
\text { (positive pools) }\end{array}$ \\
\hline Culex pipiens & 5,568 & $115(9)$ \\
\hline Aedes vexans & 405 & 19 \\
\hline Ochlerotatus caspius & 195 & 13 \\
\hline Ochlerotatus sticticus & 120 & 7 \\
\hline Coquillettidia richiardii & 34 & 7 \\
\hline Anopheles maculipennis & 22 & $11(1)$ \\
\hline Ochlerotatus geniculatus & 18 & 3 \\
\hline Anopheles hyrcanus & 3 & 2 \\
\hline Culiseta annulata & 2 & 1 \\
\hline Aedes rossicus & 1 & 1 \\
\hline Culiseta longiareolata & 1 & $\mathbf{1 8 0}(\mathbf{1 0})$ \\
\hline Total & $\mathbf{6 , 3 6 9}$ & \\
\hline
\end{tabular}

on multiple pillars. Laboratory testing of dead birds and of horses with central nervous system disease, together with monitoring of mosquito pools before the late summer-early autumn season provide relevant information to public health authorities about the risk of human infections with WNV. Here we report a greater than expected prevalence of WNV in C. pipiens and $A$. maculipennis mosquitoes collected during 2013 in parts of Serbia. Our findings were consistent with the great number of human cases in Serbia during 2013 and provide a possible explanation for the explosive spread of WNV in the affected area. This high detection rate together with the mild winter and the capability of the primary mosquito vectors to overwinter in Serbia may be alarming for the upcoming WNV season.

Public health authorities should be aware of a potentially increased risk, and should educate local inhabitants and inform the public health authorities of neighbouring countries if evidence about enhanced WNV activity emerges over time.

Acknowledgments

This research was supported by the European Union and the State of Hungary, co-financed by the European Social Fund in the framework of TÁMOP 4.2.4. A/2-11-1-2012-0001 "National Excellence Program". This study was supported by the Hungarian Scientific Research Fund (OTKA; PD77977) project. Krisztián Bányai was supported by the "Momentum program".

Conflict of interest

None declared.

Authors' contributions

Gábor Kemenesi: wrote the manuscript, coordinated the study, identified mosquitoes, coordinated laboratory processes. Vesna Milankov, Bosiljka Krtinić: field sampling of 


\section{FIGURE 2}

Abundance of female Culex pipiens mosquitoes in the sampling sites versus mean temperature, Vojvodina province, Serbia, April-October $2013(\mathrm{n}=6,369)$

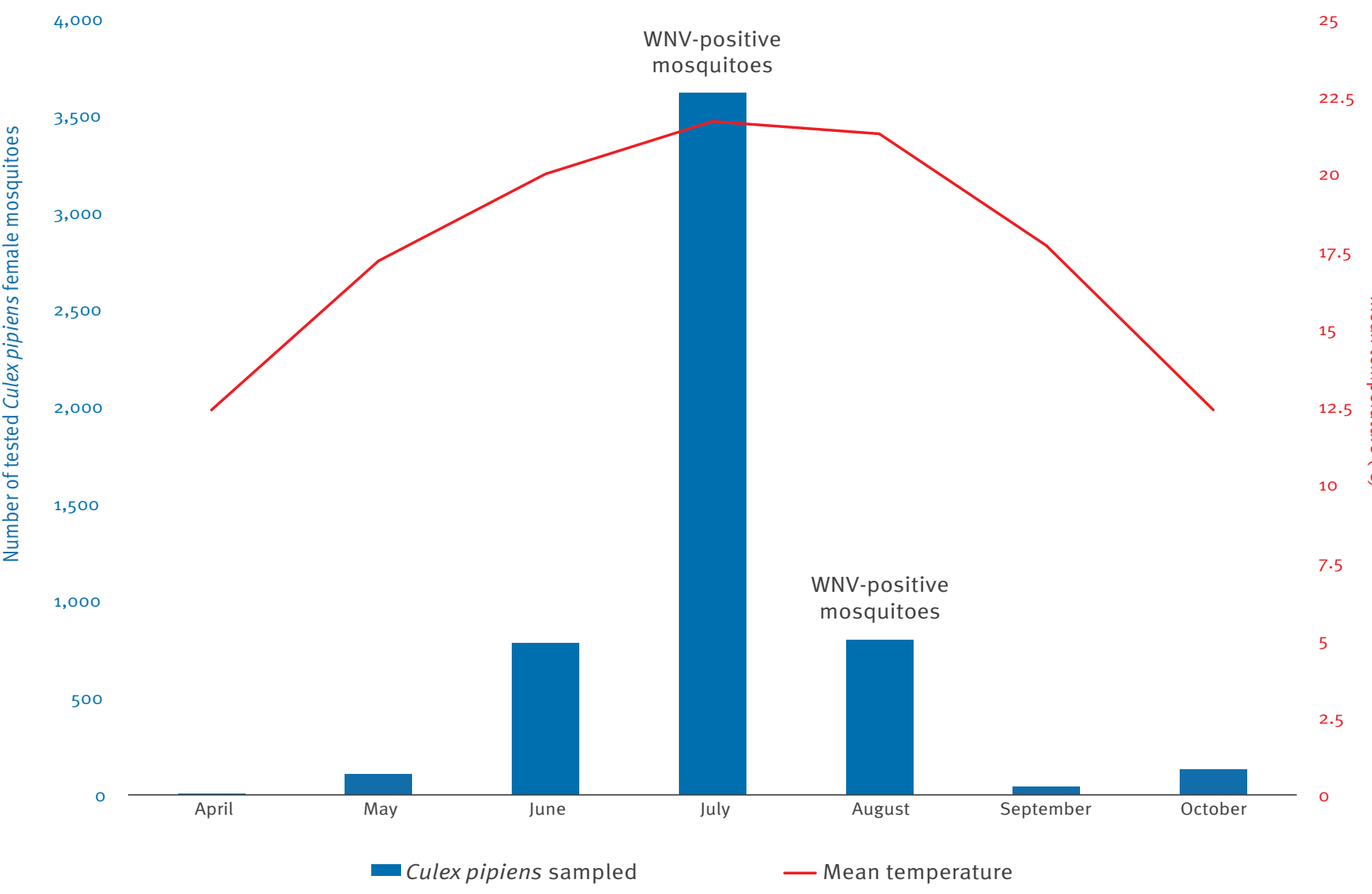

mosquitoes, interpretation of the study. Anna Kutas, Bianka Dallos, Viktória Németh: perform the virological tests. Miklós Oldal: sequencing, bioinformatics and phylogenetic analyses, contributed to the revision of the draft manuscript. Nóri Somogyi: mosquito identification, entomological verification. Krisztán Bányai: coordination and interpretation of the study, contribution to the revision of the draft manuscript. Ferenc Jakab: supervised the study and co-writer of the manuscript, contribution to the revision of the draft manuscript.

\section{References}

1. Hrnjaković-Cvjetković I, Milošević V, Petrović V, Kovačević G, Radovanov J, Cvjetković D, et al. [West Nile virus infection in humans and other vertebrates.] Arch Biol Sci Belgrade. 2014;66(1):37-42. Serbian.

2. Petric D, Hrnjakovic-Cvjetkovic I, Radovanov J, Cvjetkovic D, Jerant-Patic V, Milosevic V, et al. West Nile virus surveillance in humans and mosquitoes and detection of cell fusing agent virus in Vojvodina province (Serbia). HealthMed. 2012;6(2):462-8.

3. Popović N, Milošević B, Urošević A, Poluga J, Lavadinović L, Nedelijković J, et al. Outbreak of West Nile virus infection among humans in Serbia, August to October 2012. Euro Surveill. 2013;18(43): pii=20613.

4. Petrović T, Blázquez AB, Lupulović D, Lazić G, EscribanoRomero E, Fabijan D, et al. Monitoring West Nile virus (WNV) infection in wild birds in Serbia during 2012: first isolation and characterisation of WNV strains from Serbia. Euro Surveill. 2013;18(44): pii=20622.

5. European Centre for Disease Prevention and Control (ECDC). Communicable Disease Threats Report. Week 43, 20-26 October 2013. Stockholm: ECDC; 2013. Available from: http://www.ecdc.europa.eu/en/publications/Publications/ Communicable-disease-threats-report-26-oct-2013.pdf

6. Becker N, Petrić D, Zgomba M, Boase C, Madon M, Dahl $C$, et al. Mosquitoes and their control. New York: Kluwer
Academic/Plenum Publisher; 2003. 498 p. http://dx.doi org/10.1007/978-1-4757-5897-9

7. Bakonyi T, Ferenczi E, Erdélyi K, Kutasi O, Csörgő T, Seidel B, et al. Explosive spread of a neuroinvasive lineage 2 West Nile virus in Central Europe, 2008/2009. Vet Microbiol. 2013;165(1 2):61-70. http://dx.doi.org/10.1016/j.vetmic.2013.03.005

8. Chaskopoulou A, Dovas CI, Chaintoutis SC, Bouzalas I, Ara G, Papanastassopoulou M. Evidence of enzootic circulation of West Nile virus (Nea Santa-Greece-2010, lineage 2), Greece, May to July 2011. Euro Surveill. 2011;16(31):pii=19933.

9. Bisanzio D, Giacobini M, Bertolotti L, Mosca A, Balbo L, Kitron U, et al. Spatio-temporal patterns of distribution of West Nile virus vectors in eastern Piedmont Region, Italy. Parasit Vectors. 2011;4:230. http://dx.doi. org/10.1186/1756-3305-4-230

10. Savage HM, Ceianu C, Nicolescu G, Karabatsos N, Lanciotti R, Vladimirescu A, et al. Entomologic and avian investigations of an epidemic of West Nile fever in Romania in 1996, with serologic and molecular characterization of a virus isolate from mosquitoes. Am J Trop Med Hyg. 1999;61(4):600-11.

11. Engler O, Savini G, Papa A, Figuerola J, Groschup MH, Kampen $\mathrm{H}$, et al. European surveillance for West Nile virus in mosquito populations. Int I Environ Res Public Health. 2013;10(10):486995. http://dx.doi.org/10.3390/ijerph10104869

12. Filipe AR. Isolation in Portugal of West Nile virus from Anopheles maculipennis mosquitoes. Acta Virol. $1972 ; 16(4): 361$. 


\section{FIGURE 3}

Phylogenetic analyses of West Nile virus strains detected in Culex pipiens mosquitoes in Vojvodina province, Serbia, AprilOctober $2013(n=4)$

A. Sequences from the five lineages of West Nile virus.

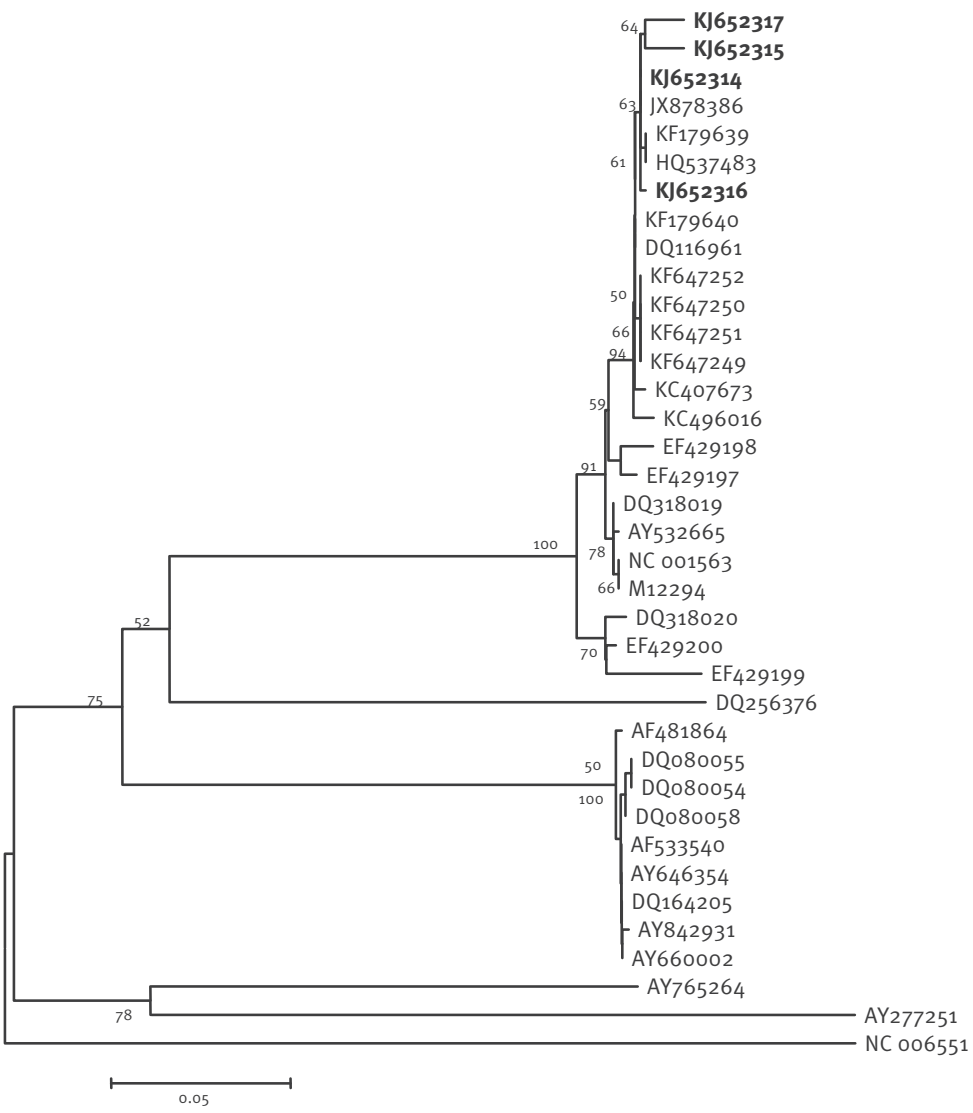

B. Lineage 2 subtree.

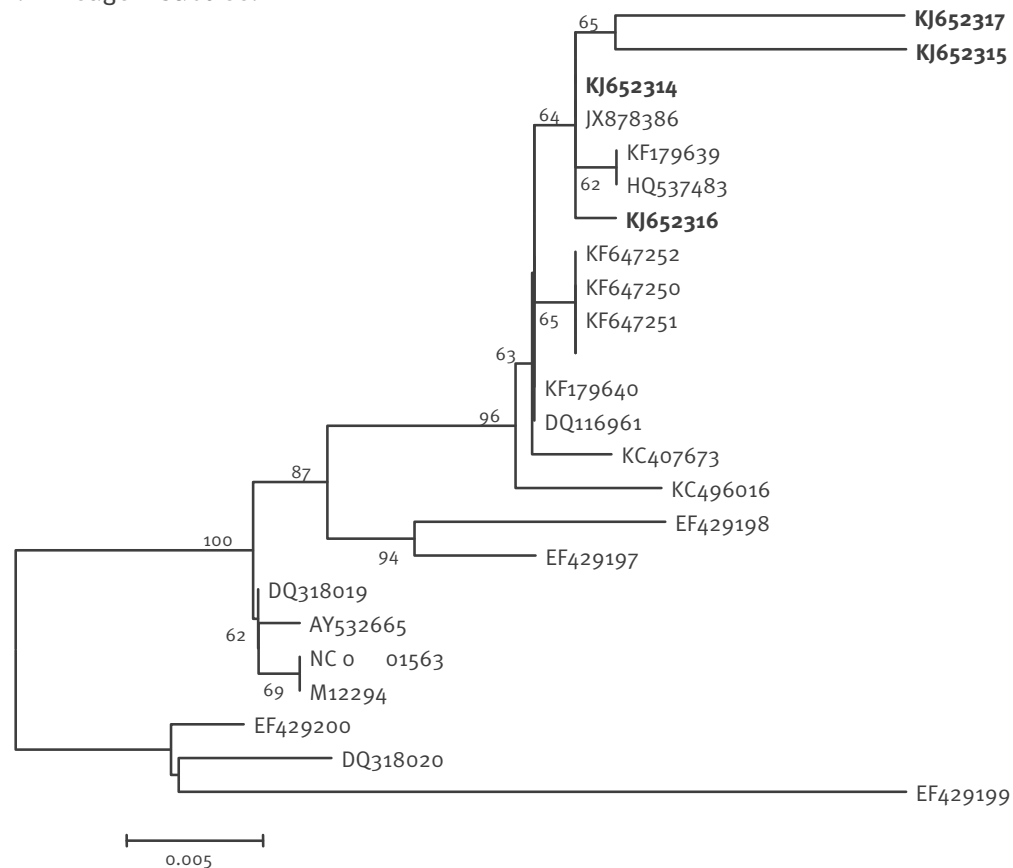

"WNV/95Cp/HUN/2013" WNV/60Cp/HUN/2013 "WNV/35Cp/HUN/2013"

"2436/12"

“Greece/2012/Kavala/39".1

"Nea SantaGreece 2010"

"WNV/71 Cp/HUN/2013"

"Italy/2013/Rovigo/35.1"

"Italy/2013/Rovigo/33.1"

"Italy/2013/Padova/34.1"

"Italy/2013/Rovigo/33.2"

"Austria/2008_gh"

"goshawkHungary/o4"

"Sad/12"

"Novi Sa€2010"

"SA93/01"

"SPU116/89"

"ArD76104"

"B956"

"Strain 956"

"33/G8; 34/F6

"H442"

"ArB3573/82"

"SA381/00"

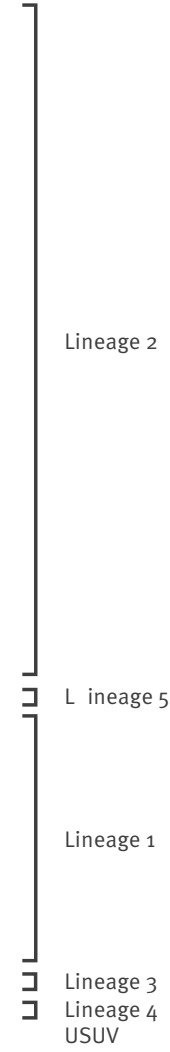

Serbia / Kikinda / 2013

Serbia / Kikinda / 2013

Serbia / Srpski Krstur / 2013

Italy / 2012

Greece / 2012

Greece / 2010

Serbia / Novi Sad / 2013

Italy / 2013

Italy / 2013

Italy / 2013

Italy / 2013

Austria / 2008

Hungary / 2004

Serbia / 202

Serbia / 2010

South Africa / 200

South Africa / 1989

Senegal/-

South Africa / 1958

Central African Republic/

South Africa / 2000

Phylogenetic trees were constructed with MEGA v5.0 software using neighbour-joining algorithm with maximum composite likelihood parameter model based on nucleic acid sequences of a 670 bp long region of the NS3 gene. Number of bootstrap replications was 1,000 , and the analysis was performed rooted using Usutu virus as outgroup. 